\title{
Reperfusion Injury Induces Apoptosis in Rabbit Cardiomyocytes
}

Roberta A. Gottlieb, ${ }^{5}$ Katharine O. Burleson, ${ }^{*}$ Robert A. Kloner, " Bernard M. Babior, ${ }^{5}$ and Robert L. Engler ${ }^{\star \neq}$

* Research Service, Department of Veterans Affairs Medical Center, San Diego, California 92161; ${ }^{\ddagger}$ Cardiology Division, Department of Medicine, University of California, San Diego, California 92093; ${ }^{8}$ Division of Biochemistry, Department of Molecular and Experimental Medicine, Research Institute of Scripps Clinic, La Jolla, California 92038; and "The Heart Institute, The Hospital of the Good

Samaritan, University of Southern California, Los Angeles, California 90017

\begin{abstract}
The most effective way to limit myocardial ischemic necrosis is reperfusion, but reperfusion itself may result in tissue injury, which has been difficult to separate from ischemic injury. This report identifies elements of apoptosis (programmed cell death) in myocytes as a response to reperfusion but not ischemia. The hallmark of apoptosis, nucleosomal ladders of DNA fragments ( $\approx 200$ base pairs), was detected in ischemic/reperfused rabbit myocardial tissue but not in normal or ischemic-only rabbit hearts. Granulocytopenia did not prevent nucleosomal DNA cleavage. In situ nick end labeling demonstrated DNA fragmentation predominantly in myocytes. The pattern of nuclear chromatin condensation was distinctly different in reperfused than in persistently ischemic tissue by transmission electron microscopy. Apoptosis may be a specific feature of reperfusion injury in cardiac myocytes, leading to late cell death. $(J$. Clin. Invest. 1994. 94:1621-1628). Key words: apoptosis • myocardial ischemia $\cdot$ reperfusion $\cdot$ myocardial infarction
\end{abstract}

\section{Introduction}

Persistent myocardial ischemia results in necrosis and scar formation leading to congestive heart failure and death. The most effective method of limiting necrosis is restoration of blood flow; however, the effects of reperfusion itself may also be associated with tissue injury (1-4). Reperfusion is associated with polymorphonuclear leukocyte (PMN) accumulation, a burst of oxygen free radical production, activation of inflammation, excessive calcium entry, and possibly late cell death; however, the exact mechanisms whereby free radicals, calcium entry, or inflammation might result in lethal injury are not well defined (5-12). Studies using superoxide dismutase and other antioxidants have provided interesting leads, suggesting that the oxidative stress and burst of free radical production associated with reperfusion are important mediators of myocardial damage; however, no clear answers have emerged (13). In animal models the net benefit of timely flow restoration outweighs the combination of ischemic and reperfusion injury. Research efforts to improve survival in the current era of reperfusion by thrombolysis or angioplasty have therefore focused on limitation of irreversible reperfusion injury which results in additional

Address correspondence to Robert Engler, MD, ACOS Research Service (151), Dept. of Veterans Affairs Medical Center, 3350 La Jolla Village Drive, San Diego, CA 92161. 1994.

Received for publication 2 August 1993 and in revised form 3 June

The Journal of Clinical Investigation, Inc.

Volume 94, October 1994, 1621-1628 death of potentially viable tissue. There is no debate that prolonged and severe ischemia alone can kill myocytes by necrosis. However, debate continues over whether the irreversible process culminating in cell death can be initiated by the act of reperfusion itself.

Apoptosis is a physiologic process for disposing of senescent or unwanted cells through self-destruction. For example in immune development deletion of autoreactive $\mathrm{T}$ cells, thymic involution, embryologic remodeling, and prostatic regression after androgen withdrawal are all examples of the apoptotic process (14-19). In mature organisms, apoptosis as a manifestation of programmed cell death occurs physiologically in several renewing cell types such as intestinal epithelium and leukocytes, where it maintains a balance between cell replication and cell death $(18,19)$.

Necrosis and apoptosis are distinct mechanisms of cell death (20). Ischemic necrosis is characterized by ATP depletion, cell swelling, and loss of cell membrane integrity, whereas apoptosis usually requires energy, and is associated with cell shrinkage and phagocytosis without loss of membrane integrity. The hallmark of apoptosis in intact cells is endonucleolytic digestion of nuclear but not mitochondrial DNA into oligonucleosome-sized fragments ( $\sim 200$ bp multiples ), in contrast to nonspecific degradation of DNA into pieces of random size after loss of membrane integrity $(17,21-24)$. Although apoptosis was first described in 1972 (25) on morphologic grounds, it can be difficult to detect apoptotic cells in situ by light microscopy, as the characteristic appearance is transient (minutes to a few hours). It is an inducible phenomenon associated with activation or de novo expression of an endonuclease and expression of cell surface adherence glycoproteins $(21,22,26,27)$. In some cell types endonuclease activity can be induced by DMSO, calcium ionophore, reactive oxidants, or Ca-calmodulin $(21,28)$. Evidence of apoptosis in mature, nonrenewable parenchymal cells after reperfusion implies late cell death that is preventable with important survival implications.

We performed studies to determine if elements of the apoptotic process were induced by reperfusion in cardiac myocytes. We found evidence of apoptosis unique to reperfusion injury but not in ischemic injury alone. This observation may make it possible to distinguish reperfusion injury from that of ischemia and to assess the contribution of reperfusion injury to infarct size.

\section{Methods}

Animal model. All animal procedures were approved by the American Association of Accreditation of Laboratory Animal Care certified institutional animal care committee. New Zealand white rabbits weighing 2.8$3.6 \mathrm{~kg}$ were anesthetized with intravenous pentobarbital. Arterial blood gases were kept physiologic and arterial pressure and electrocardiogram were monitored. The heart was exposed through a left thoracotomy and a suture ligature passed around the anterior branch of the left coronary 
artery so it could be snare occluded and reperfused. Ischemia was induced by snare occlusion and confirmed by visual inspection and the electrocardiogram. After the ischemic intervention the heart was rapidly excised, hung in a Langendorff perfusion mode, the coronary bed flushed with lactated Ringer's solution, and the normal area marked by perfusion with monastral blue dye.

Six groups of animals were studied with ischemia/reperfusion protocols as in Table II to look for $200 \mathrm{bp}$ DNA ladders of apoptosis. For in situ nick translation assay and electron microscopy (EM) ${ }^{1}$ studies, 30 min ischemia and $4 \mathrm{~h}$ reperfusion was compared to $4.5 \mathrm{~h}$ of continuous ischemia. In the rabbit, $30 \mathrm{~min}$ of ischemia followed by reperfusion results in about $50 \%$ cell death in the area at risk, and $4.5 \mathrm{~h}$ of ischemia leads to complete transmural infarction in the risk zone.

DNA extraction. Hearts were removed from the perfusion device and transmural myocardial samples from completely normal and ischemic areas were isolated using the dye perfusion as a guide, frozen in liquid nitrogen, and stored at $-70^{\circ} \mathrm{C}$ for up to $6 \mathrm{wk}$. Tissue was minced while thawing under lysis buffer (50 mM Tris pH 8.0, $20 \mathrm{mM}$ EDTA, $1 \%$ SDS ). Tissue was subjected to a second freeze-thaw and then digested in lysis buffer with $0.1 \mathrm{mg} / \mathrm{ml}$ proteinase $\mathrm{K}$ for $18 \mathrm{~h}$ at $55^{\circ} \mathrm{C}$ with shaking. DNA was phenol/chloroform extracted and 4-6 $\mu \mathrm{g}$ of DNA were electrophoresed on $2 \%$ agarose. Cardiac tissue was identified by coded numbers and samples were processed in parallel.

Granulocytopenia. Rabbits were treated with nitrogen mustard 2.7 $\mathrm{mg} / \mathrm{kg}$ i.v. in two divided doses on days 1 and 3 to cause granulocytopenia and subjected to ischemia and reperfusion on day 5 . Control animals for this group were treated with a single dose of $2.7 \mathrm{mg} / \mathrm{kg}$ nitrogen mustard 20 min before coronary occlusion, sufficient time for alkylation of DNA before ischemia.

In situ nick end labeling. Hearts were perfusion fixed with $4 \%$ paraformaldehyde on the Langendorff apparatus. Paraffin-embedded myocardial sections were mounted on slides. These transverse whole heart sections were carefully kept oriented to mark normal and ischemic areas. Normal and ischemic area orientation was noted on the label and confirmed by monastral blue dye in normal areas. In situ nick end labeling was performed as described $(29,30)$ with $0.5 \mu \mathrm{M}$ biotin-14dATP (Gibco BRL, Gaithersburg, MD), dCTP, dGTP, dTTP (each 5 $\mu \mathrm{M})$ and $9 \mathrm{U} / \mathrm{ml}$ DNA polymerase I $\left(15 \mathrm{~min}, 37^{\circ} \mathrm{C}\right)$. Endogenous peroxidases were inactivated with $0.28 \%$ periodic acid. Labeled DNA was detected with streptavidin-peroxidase $\left(30 \mathrm{~min}, 37^{\circ} \mathrm{C}\right)$ and developed with diaminobenzidine/peroxide. (Kierkegaard and Perry Labs, Gaithersburg, MD). Positive controls were prepared by treating selected slides with DNAase I, $0.1 \mathrm{U} / \mathrm{ml}$, before biotin incorporation. Endocardial, midwall, and epicardial thirds were identified on low power and typical areas counted at $250 \times$ using a grid. Labeled nuclei were easily identified from the unstained background. We found in pilot experiments that counterstaining led to difficulty in identifying faintly positive nuclei. Mean counts from the normal or ischemic area of a typical transverse section from each animal were transformed as $\log$ (counts) +1 and differences tested by analysis of variance, (i.e., $n=$ animals not sections). All data are mean \pm SD.

Electron microscopy. Animals were anaesthetized as above and two groups were studied: Ischemia for $30 \mathrm{~min}$ and reperfusion for $4 \mathrm{~h}$ ( $n$ $=4)$, and $4.5 \mathrm{~h}$ continuous ischemia $(n=4)$. Hearts were postmortem perfusion-fixed with Karnovsky's fixative followed by ligation of the coronary ligature and monastral blue dye perfusion. Tissue from normal and ischemic regions were immersed in Karnovsky's fixative. Midwall samples were cut to $1-\mathrm{mm}$ cubes, post fixed in osmium tetroxide and oriented longitudinally in blocks. Thin sections were mounted and 810 grids were scanned and nearly all abnormal myocyte nuclei photographed. Magnification was 10,000 for all photomicrographs. Photographs were printed with brightness and contrast adjustment for uniform sarcomere intensity. All prints were listed by negative number and

1. Abbreviations used in this paper: EM, electron microscopy; HPF, high power field.
Table I. Electron Microscopy Scoring

Nuclear Pattern
N1 Homogeneously dispersed chromatin
N2 Homogeneous dense condensation with marginated
chromatin, central clearing
N3 Variable density chromatin condensation, diffuse distribution
Mitochondria
M0 No dense bodies
M1 Dense bodies
Sarcomere
S0 Z bands in register, normal
S1 Wide I bands
S2 Z bands out of register
S3 $\quad$ Single contraction band
S4 Multiple contraction bands

scored in a blinded fashion according to Table I by one observer and a subset read blindly by a second observer. Concordance between observers was within $2 \%$ for mitochondrial and sarcomere classification.

Preliminary studies on several hearts revealed two distinct types of nuclear chromatin change. Dense homogeneous condensation with margination of chromatin and central clearing was one pattern (N2) (seen predominantly in persistently ischemic tissue) and the other pattern was variable density chromatin condensation distributed diffusely with less central clearing (N3) (Table I). After initial blinded classification, photographs were reclassified by two of us. Agreement with initial classification was $92 \%$; a few photographs were eliminated because of uncertain classification. One animal in the persistent coronary occlusion group was eliminated because all sections showed extensive contraction bands indicating inadvertent reperfusion. Myocytes with normal nuclei and cytoplasm were not included in the analysis.

\section{Results}

Detection of apoptosis in myocardium following ischemia and reperfusion. Of seven rabbits subjected to $30 \mathrm{~min}$ ischemia and $4 \mathrm{~h}$ reperfusion, all showed a typical nucleosome ladder on DNA electrophoresis of tissue obtained from the ischemic left ventricle (Fig. 1, Table II). Nucleosome ladders were never seen in nonischemic left ventricle or right ventricle in these or any of the rabbit hearts studied. This duration of ischemia results in loss of dehydrogenase activity (triphenyl tetrazolium chloride staining) in about $50 \%$ of the ischemic area at risk $(31,32)$. Rabbit myocardium subjected to $4.5 \mathrm{~h}$ continuous ischemia ( $n$ $=5$ ) did not show any nucleosomal cleavage; ischemic tissue did show nonspecific DNA degradation. $5 \mathrm{~min}$ of ischemia in the rabbit heart does not result in any cell death; in three animals studied after $5 \mathrm{~min}$ ischemia and $4 \mathrm{~h}$ reperfusion nucleosomal cleavage was not detected. To further test whether the apoptosis was due specifically to reperfusion, animals $(n=3)$ were studied after $30 \mathrm{~min}$ ischemia only (no reperfusion) and ischemic areas did not show DNA nucleosomal fragmentation. Hemodynamics and heart rate were within physiologic range for this model and not different between groups (Table III).

Contribution of granulocytes. Granulocytes (PMN) are known to undergo apoptosis $(15,33)$. In our experiments the postmortem buffer perfusion might not have removed PMNs in the ischemic area due to extravascular migration or capillary no-reflow from leukocyte capillary plugging (34). To test the possibility that PMNs were the source of the nucleosomal lad- 


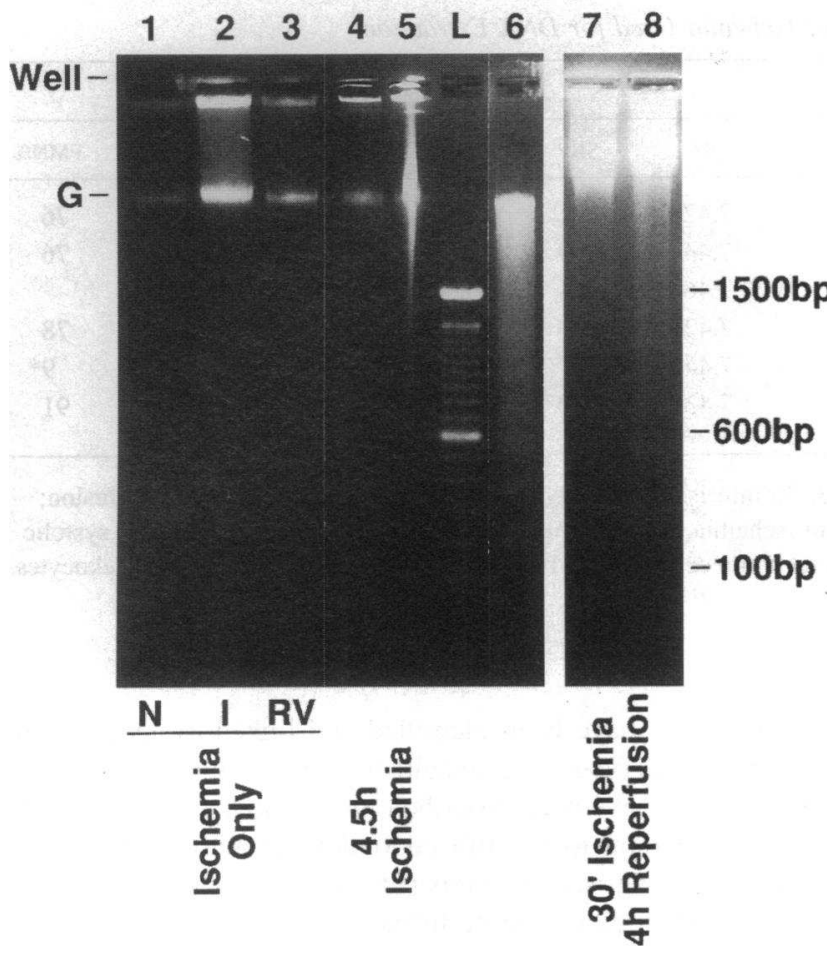

Figure 1. DNA extracted from rabbit heart, $2 \%$ agarose gel, composite of several gels. Lanes 1-3 are from hearts exposed to $30 \mathrm{~min}$ ischemia without reperfusion. (Lane $1, N$ ), normal left ventricle; (lane 2,I), ischemic left ventricle, (lane $3, R V$ ), right ventricle (nonischemic). Lanes 4-5 are from hearts with $4.5 \mathrm{~h}$ of persistent ischemia. (lane 4) Normal left ventricle, (lane 5) $4.5 \mathrm{~h}$ ischemic left ventricle. (Lane $L$ ) 100 bp marker ladder. Lanes $6-8$ are from hearts exposed to $30 \mathrm{~min}$ ischemia and $4 \mathrm{~h}$ reperfusion. Lane 6 , ischemic and reperfused left ventricle, an obvious ladder is present in the $200-800$ bp range. Lane 7 , normal left ventricle. Lane 8 , ischemic and reperfused left ventricle, an example of a faint ladder. The two ladders are examples of the most apparent and least apparent ladders.

der, the granulocytopenic animals were tested for reperfusioninduced apoptosis. The granulocyte count was $100 \pm 50$ cells $/ \mu \mathrm{l}$ in granulocytopenic animals (essentially zero in four of seven animals) and $4140 \pm 1300$ cells/ $\mu 1$ in controls treated with the full dose of nitrogen mustard immediately before the coronary occlusion. All five of the nitrogen mustard control hearts showed a ladder pattern in the ischemic area, and five of seven

Table II. Nucleosome Ladders in Ischemic Tissue from Rabbit Myocardium

\begin{tabular}{|c|c|c|c|}
\hline Group & & $\begin{array}{c}\text { No. of } \\
\text { animals }\end{array}$ & $\begin{array}{l}\text { No. with } \\
\text { DNA ladder }\end{array}$ \\
\hline 1 & $30 \mathrm{~min}$ Ischemia, $4 \mathrm{~h}$ reperfusion & 7 & 7 \\
\hline 2 & $4.5 \mathrm{~h}$ Ischemia & 5 & 0 \\
\hline 3 & $30 \mathrm{~min}$ Ischemia & 3 & 0 \\
\hline 4 & $5 \mathrm{~min}$ Ischemia, $4 \mathrm{~h}$ reperfusion & 3 & 0 \\
\hline 5 & $\begin{array}{l}30 \text { min Ischemia, } 4 \mathrm{~h} \text { reperfusion } \\
\text { Granulocytopenic }\end{array}$ & 7 & 5 \\
\hline 6 & $\begin{array}{l}30 \text { min Ischemia, } 4 \text { h reperfusion } \\
\text { Nitrogen mustard control }\end{array}$ & 5 & 5 \\
\hline
\end{tabular}

granulocytopenic animals had a typical ladder pattern (Table II). The reason for absence of nucleosomal cleavage in two animals is unknown; perhaps PMNs contribute to or amplify the apoptosis-inducing signal for myocytes. Administration of the alkylating agent nitrogen mustard apparently does not block apoptosis in this setting. The detection of nucleosomal cleavage on agarose gel in neutropenic animals indicates that cell types other than or in addition to PMNs were undergoing apoptosis. However, we cannot exclude some contribution of PMN DNA to the ladder pattern seen in tissue from rabbits with normal PMN counts.

In-situ labeling of nicked DNA. Since the techniques we used to identify nucleosomal digestion involved whole tissue, the cardiac cell type undergoing apoptosis could not be identified. To address this issue we used in situ nick end labeling to identify the cell type(s) undergoing DNA fragmentation (29, 30 ). In positive controls made by exposing sections to DNAase I before nick end labeling, there were $48.7 \pm 4.3$ positive myocyte nuclei/high power field (HPF, $250 \times$ ) and $10.7 \pm 2.7$ positive endothelial nuclei/HPF distributed evenly across the wall (endocardium, midwall and epicardium) (Fig. 2). In normal tissue myocyte nuclei did not label and endothelial cell nuclei were rarely positive $(0.2 \pm 0.3 / \mathrm{HPF})$. Myocyte nuclei with nicked or degraded DNA were present in both $30 \mathrm{~min}$ ischemic/ $4 \mathrm{~h}$ reperfused tissue $(7.0 \pm 7.1 / \mathrm{HPF}$, mean across the wall $)$ and $4.5 \mathrm{~h}$ ischemic tissue $(10.5 \pm 5.1 / \mathrm{HPF}, P=\mathrm{NS})$. There was a significant trend across the wall for positive myocyte nuclei to be more frequent toward the endocardium in both groups ( $P$ $<0.05)$. Labeled endothelial nuclei were less common in the reperfused tissue (1.0 $\pm 1.1 / \mathrm{HPF}$, transmural mean $)$ than in 4.5 $\mathrm{h}$ ischemic tissue (2.2 $\pm 0.4 / \mathrm{HPF}, P=0.05$, and $P<0.01$ for a gradient across the wall with higher counts in the endocardium). Three of five reperfused animals had $\leq 0.3$ endothelial nuclei/ HPF, (i.e., indistinguishable from normal tissue). There was marked variation within and between individual hearts as reflected by the large standard deviation; whether this is due to technique or true biologic variation is unclear. DNAase I positive controls however showed much less variation. These findings confirmed myocytes as the major source of nucleosomal DNA degradation on agarose gels.

Electron microscopy. Seven hearts were included in the analysis (three ischemic and four reperfused). Tissue from the nonischemic region was always normal. Approximately 180 abnormal nuclei were photographed and scored from ischemic or ischemic/reperfused regions. In the reperfused tissue, $96.9 \%$ of the abnormal nuclei showed the variable density, diffuse pattern of condensation, N3 (Figs. 3 and 4 and Table IV). Typical contraction bands were present in $91 \%$ of the photographs. In the persistently ischemic tissue only $28 \%$ of the nuclei showed the N3 pattern, while $72 \%$ of the nuclei had homogeneously dense chromatin condensation with central clearing (N2 pattern, Table IV). When the N2 nuclear pattern was present it was associated with wide I bands (93\%). Of the $28 \%$ of nuclei in persistently ischemic tissue that showed the N3 pattern, the sarcomere abnormalities were contraction bands (57\%) or $\mathrm{Z}$ bands out of register (14\%) in the majority of the cells. Both of these changes have been associated with reperfusion, suggesting that these cells were in a marginal area that had the morphometry of reperfusion. Thus, the EM data indicate a distinct pattern of nuclear chromatin change (N3) associated with reperfusion; when this N3 pattern was seen in the persistently ischemic tissue, it was associated with cytoplasmic 
Table III. Hemodynamic and Blood Values from Rabbits with Myocardial Ischemia Used for DNA Extraction

\begin{tabular}{|c|c|c|c|c|c|c|c|c|c|c|c|c|}
\hline \multirow[b]{2}{*}{ Group No. } & \multicolumn{6}{|c|}{ Before ischemia } & \multicolumn{6}{|c|}{ During reperfusion or end ischemia } \\
\hline & $\mathrm{pH}$ & SBP & HR & Hct\% & WBC & PMN\% & $\mathrm{pH}$ & SBP & HR & Hct\% & WBC & PMN\% \\
\hline $1(5)$ & 7.48 & 97 & 263 & 34.7 & 4.4 & 69 & 7.42 & 91 & 253 & 29.9 & 8.9 & 76 \\
\hline $2(3)$ & 7.39 & 110 & 263 & 36.9 & 8.2 & 89 & 7.44 & 99 & 263 & 32.4 & 11.6 & 76 \\
\hline $3(3)$ & 7.46 & 106 & 235 & 33.5 & 7.2 & 81 & 7.46 & 101 & 230 & & & \\
\hline $4(3)$ & 7.41 & 98 & 255 & 34.4 & 7.8 & 87 & 7.42 & 90 & 243 & 31.7 & 9.2 & 78 \\
\hline $5(7)$ & 7.52 & 110 & 253 & 33.6 & 2.0 & $5^{*}$ & 7.44 & 107 & 258 & 30.0 & 1.1 & 9* \\
\hline $6(5)$ & 7.45 & 107 & 260 & 38.7 & 6.0 & 69 & 7.43 & 90 & 267 & 33.3 & 7.4 & 91 \\
\hline
\end{tabular}

Group 1, $30 \mathrm{~min}$ ischemia, $4 \mathrm{~h}$ reperfusion; group 2, $4.5 \mathrm{~h}$ ischemia; group 3, $30 \mathrm{~min}$ ischemia only; group 4, $5 \mathrm{~min}$ ischemia, $4 \mathrm{~h}$ reperfusion; group 5, $30 \mathrm{~min}$ ischemia, $4 \mathrm{~h}$ reperfusion, granulocytopenic; group 6, $30 \mathrm{~min}$ ischemia, $4 \mathrm{~h}$ reperfusion, nitrogen mustard control. SBP, systolic blood pressure (mm Hg), HR, heart rate (beats/min); Hct, hematocrit; WBC, total white cell count $\times 10^{3} / \mu \mathrm{l} ; \mathrm{PMN}$, \% polymorphonuclear leukocytes. *4 of 7 animals had no detectible PMNs.

changes that suggest some perfusion, e.g., location at the margin of the infarction. Electron dense deposits in mitochondria, a marker for irreversible injury, were found in equal frequency with $\mathrm{N} 2$ or N3 nuclear patterns (Table IV).

No typical apoptotic bodies in myocytes were found. A few PMN did show signs of apoptosis (cytoplasmic concentration, nuclear fragments with condensed chromatin).

\section{Discussion}

Our results indicate that terminally differentiated cardiomyocytes die by apoptosis after ischemia and reperfusion, but that apoptosis does not occur during persistent ischemia. The presence of internucleosomal DNA fragmentation is considered a hallmark of apoptosis; however, it does not provide information about which cell type(s) are undergoing apoptosis. Of blood cells within the heart, only leukocytes undergo apoptosis. Although leukocytes accumulate in ischemic myocardium, and are believed to contribute to the free radical burst observed on reperfusion, apoptosis is observed in cardiac tissue even in profoundly neutropenic animals. This indicates that leukocytes or blood cells are not the major source of nucleosome-sized fragments of DNA and that, although they may contribute to the signal inducing apoptosis in cardiac cells, they are not the exclusive trigger. We next sought to identify the resident cardiac cell type undergoing apoptosis.

In situ nick end labeling has been used to detect apoptotic cells in tissue sections $(29,30)$, although it cannot distinguish between the nucleosomal cleavage of apoptosis and the nonspecific DNA degradation of necrosis. However, it does provide valuable information about the tissue distribution and cell types undergoing cell death. Accompanying morphologic features of apoptosis versus necrosis are helpful when present, but DNA cleavage can occur in the absence of significant morphologic alterations (35). We used in situ nick end labeling to demonstrate that myocytes are the predominant cell type with nucleosomal DNA fragmentation in ischemic/reperfused tissue. Some minor contribution of endothelial cells cannot be excluded, as one animal did show significant endothelial nuclear staining. However in three of five reperfused animals nearly all the nicked DNA was in myocytes.

The nucleosomal DNA cleavage of apoptosis is attributed to an unique endonuclease $(17,21,27,36,37)$. Although several endonucleases have been identified and linked to apoptosis in a variety of cell types, to date neither apoptosis nor an associated endonuclease have been described in cardiac myocytes (21). It will be important to identify endonuclease activity in cardiac myocytes during ischemia/reperfusion.

The EM studies were performed to look for ultrastructural nuclear changes distinctive of reperfusion. Two distinct morphologic patterns of chromatin condensation were observed. The pattern with variable density chromatin condensation (N3) was the predominant pattern in reperfused tissue. In the persistently ischemic tissue the $\mathrm{N} 3$ pattern was usually associated with contraction bands. Contraction bands are considered to be a marker for reperfused myocardium. The concordance of contraction bands with N3 nuclear pattern suggests that the N3 pattern occurs only in myocytes with a preserved or partially restored energy charge from perfusion. Apoptosis or programmed cell death is believed to be an energy-requiring process. In this regard, Entman and co-workers have found that reperfused (but not ischemic) canine cardiac muscle expresses de novo ICAM-1 message and protein (38-40). Thus their studies and ours suggest that myocytes are undergoing specific energy-requiring processes after reflow. These same cells show other characteristics of dying cells, e.g., basic fuchsin positive staining, electron dense bodies in mitochondria, or contraction bands. Neither their studies nor ours provide quantitative measures. Quantitation of the extent of this reperfusion-specific process of apoptosis [or ICAM-1 induction in the studies by Kukielka et al. (40)] is necessary to estimate the potential clinical importance. Nonetheless, identification of a reperfusion-specific injury process suggests that separation of reperfusion injury from ischemic injury will be possible in future studies.

Another interesting observation is the absence of apoptotic bodies in myocytes, despite evidence of chromatin condensation and nucleosomal ladders. One possibility is insufficient reperfusion time; we have only studied tissue out to $4 \mathrm{~h}$ and apoptotic bodies might become evident only at later times. In ischemic/ reperfused renal tissue apoptotic bodies in the epithelial cells were not apparent until $12 \mathrm{~h}$ of reperfusion (41-42). However, histologic studies on reperfused myocardium have never reported apoptotic bodies. It is possible that they were never really looked for at the appropriate time after reperfusion. A second possibility is that inflammatory cell activation in the area due to a necrotic neighboring myocyte alters the process of apoptosis. 

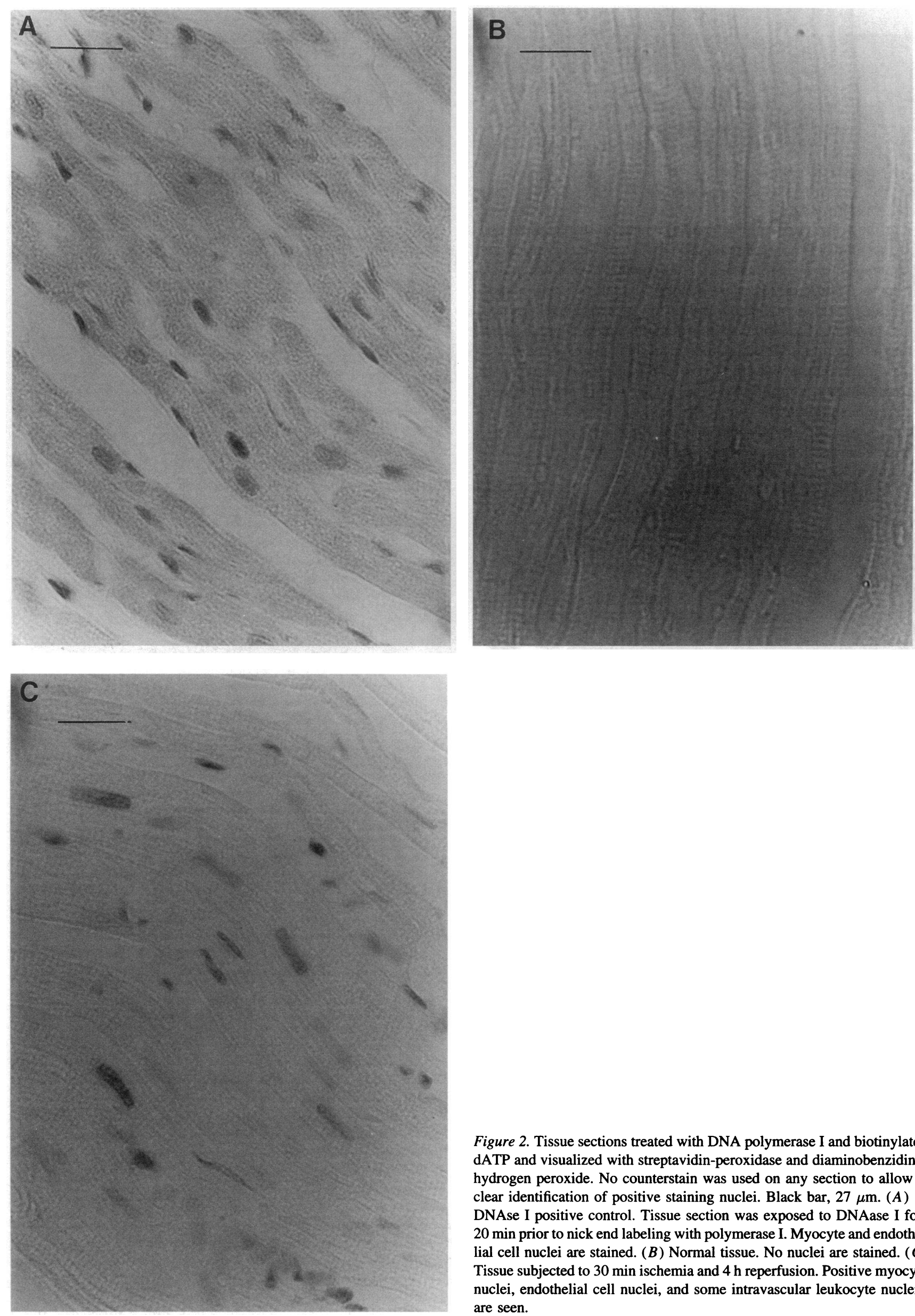

Figure 2. Tissue sections treated with DNA polymerase I and biotinylated dATP and visualized with streptavidin-peroxidase and diaminobenzidinehydrogen peroxide. No counterstain was used on any section to allow clear identification of positive staining nuclei. Black bar, $27 \mu \mathrm{m} .(A)$ DNAse I positive control. Tissue section was exposed to DNAase I for 20 min prior to nick end labeling with polymerase I. Myocyte and endothelial cell nuclei are stained. $(B)$ Normal tissue. No nuclei are stained. $(C)$ Tissue subjected to $30 \mathrm{~min}$ ischemia and $4 \mathrm{~h}$ reperfusion. Positive myocyte nuclei, endothelial cell nuclei, and some intravascular leukocyte nuclei are seen. 

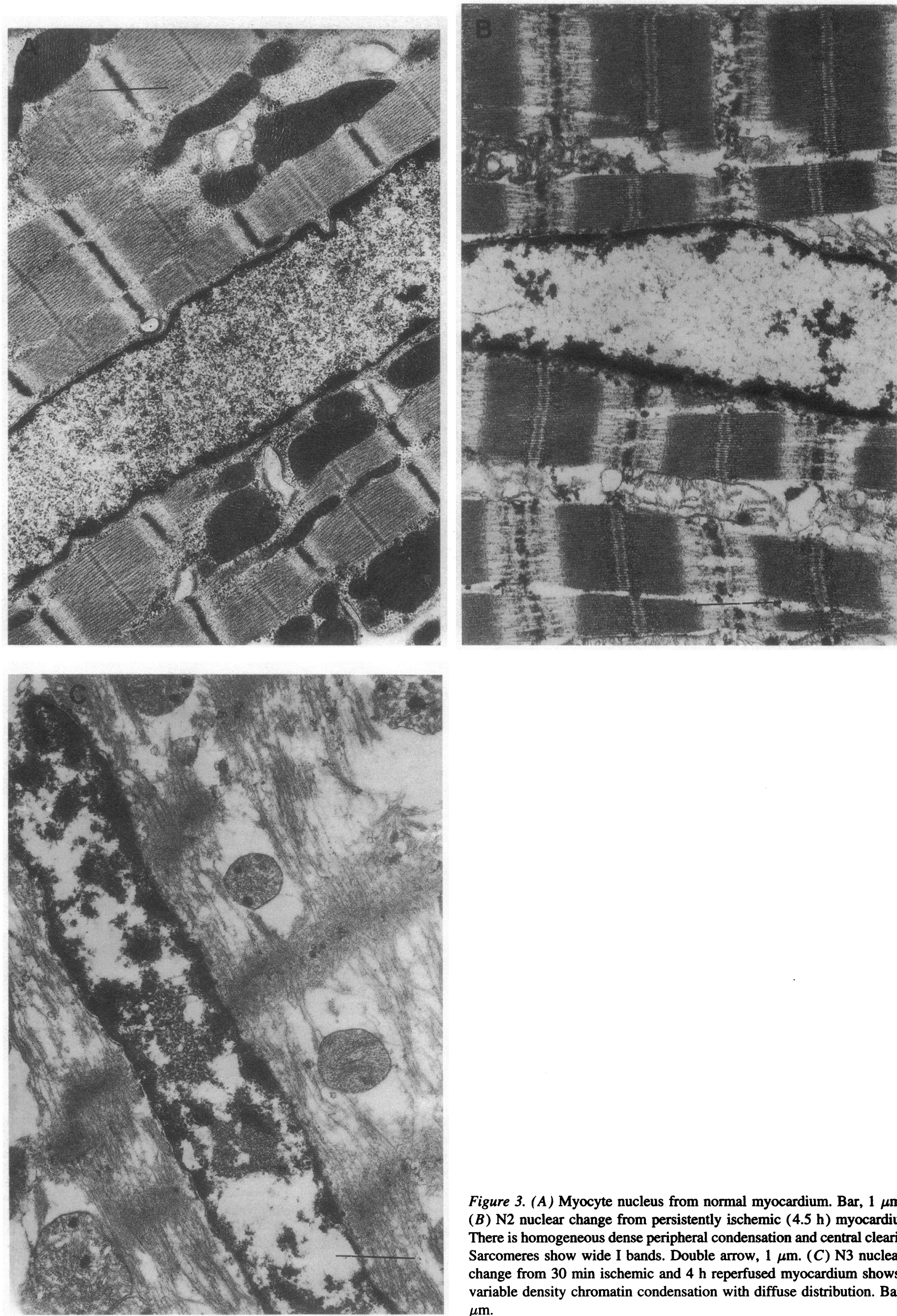

Figure 3. (A) Myocyte nucleus from normal myocardium. Bar, $1 \mu \mathrm{m}$. $(B) \mathrm{N} 2$ nuclear change from persistently ischemic $(4.5 \mathrm{~h})$ myocardium. There is homogeneous dense peripheral condensation and central clearing Sarcomeres show wide I bands. Double arrow, $1 \mu \mathrm{m}$. (C) N3 nuclear change from $30 \mathrm{~min}$ ischemic and $4 \mathrm{~h}$ reperfused myocardium shows variable density chromatin condensation with diffuse distribution. Bar, 1 $\mu \mathrm{m}$. 


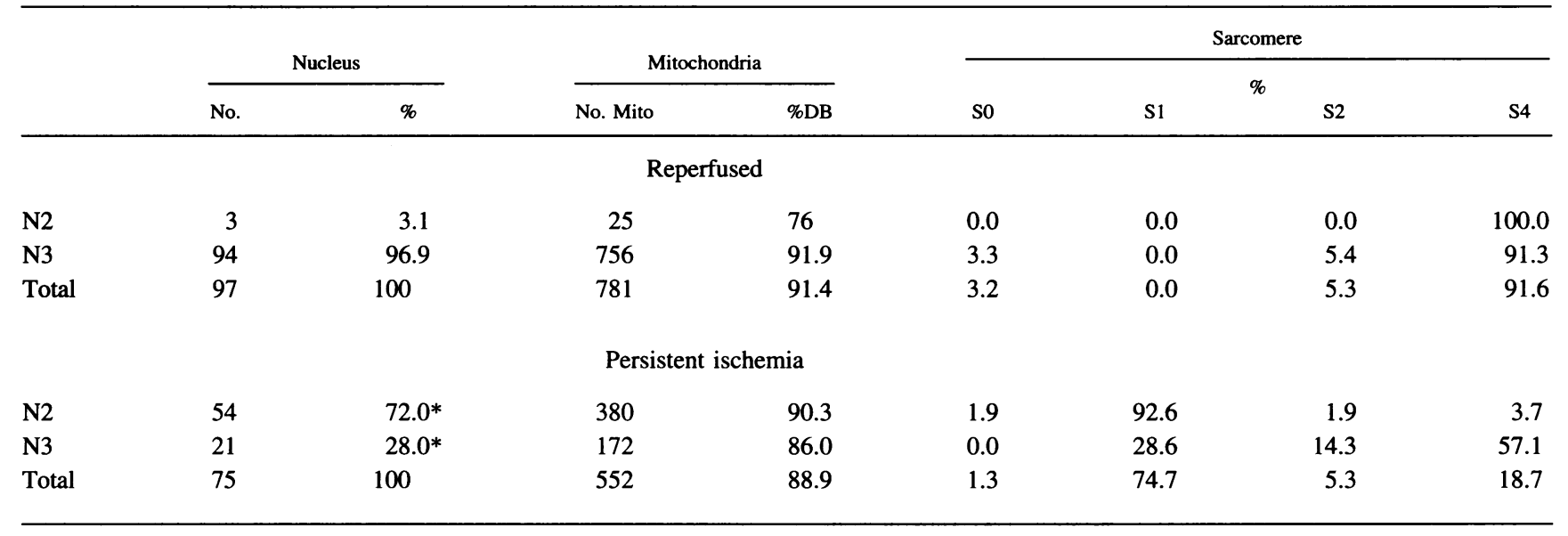

Electron microscopic results. \%DB, \% of mitochondria with large dense body deposits. S0, S1, S2, S4 refer to sarcomere type (Table I), S0, normal; S1, Wide I bands; S2, Z bands out of register; S4, multiple contraction bands. No S3 changes were seen. N1, normal nucleus was excluded from this analysis; N2, dense chromatin condensation with central clearing; N3, both dense and reticulated pattern of chromatin condensation. Data from 4 reperfused and 3 persistently ischemic hearts. At least 15 nuclei were included from each animal.

Display of adhesion molecules on myocytes may allow PMN (or macrophage) attachment and superoxide production, as shown in in vitro and in vivo studies by Entman et al. in reperfused canine myocardium $(5,38-40)$. Thus, apoptosis would be converted to necrosis by PMN attachment and activation. This would be in contrast to physiologic situations of programmed cell death, where inflammation is not present and apoptosis follows its natural course $(16,25)$. A third possibility is that only part of the apoptotic process is activated. Internucleosomal DNA cleavage and the unique chromatin condensation pattern we observed could occur, but other necessary elements for the formation of apoptotic bodies might be absent in cardiomyocytes.

In previous studies of renal ischemia and reperfusion, evidence of apoptosis was seen on DNA electrophoresis. A nucleosomal ladder pattern was seen in both permanently occluded and reperfused renal tissue, but the ladder was somewhat obscured by a smear of nonspecific DNA degradation in the permanently occluded kidney $(41,42)$. Apoptotic bodies in epithelial cells were seen by $12 \mathrm{~h}(42)$.

Apoptosis can be induced in inflammatory cells by cytokines and various toxins including reactive oxidants $(28,43,44)$. De novo cell surface expression of the vitronectin receptors on neutrophils and lymphocytes has been shown to be a requirement for phagocytosis of apoptotic cells by macrophages (33). One interesting implication of these findings for cardiac isch-

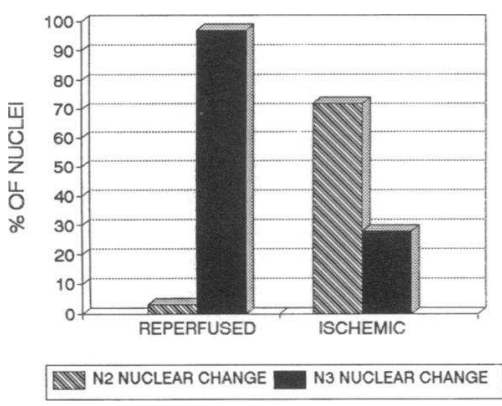

Figure 4. Fraction of abnormal myocyte nuclei with $\mathrm{N} 2$ or $\mathrm{N} 3$ condensation pattern in reperfused or persistently ischemic myocardium. emia comes from the observation that cardiac lymph in ischemic dog heart contains IL-6, which induces the expression of ICAM-1 adherence glycoproteins on cardiomyocytes $(38,39)$. These ICAM-1 adherence glycoproteins may mark apoptotic myocytes for clearance by phagocytes or attack by PMN.

There is evidence using several surrogate markers of tissue viability (dehydrogenase activity, glucose metabolism, and electron microscopy) that myocytes which eventually die seem viable for several hours after reperfusion; whether the irreversible event leading to late cell death occurs during ischemia or reperfusion has been unclear $(4,12,45,46)$. The occurrence of apoptosis in ischemic myocytes only if they are subjected to reperfusion suggests a reperfusion-specific process that could lead to delayed cell death. This hypothesis is consistent with the studies showing postischemic metabolic activity and late cell death. The free radical burst generated upon reperfusion could be one mechanism to trigger apoptosis. The relative contributions of apoptosis and necrosis to late, reperfusion-induced cell death in potentially viable myocytes remain to be determined. Apoptosis as a component of reperfusion injury is a process that is potentially preventable.

\section{Acknowledgments}

The authors thank David Stein and Barry Peters for technical assistance and La Rosa Faust for advice and helpful suggestions.

Supported in part by National Heart, Lung, and Blood Institute grant HL-17682, Department of Veterans Affairs, and Gensia, Inc. R.A. Gottlieb was supported by a Physician Postdoctoral Fellowship from the Howard Hughes Medical Institute.

\section{References}

1. Braunwald, E., and R. A. Kloner. 1985. Myocardial reperfusion: a double edged sword? J. Clin. Invest. 76:1713-1719.

2. Kloner, R. A., K. Przyklenk, and P. Whittaker. 1989. Deleterious effects of oxygen radicals in ischemia/reperfusion. Resolved and unresolved issues. Circulation. 80:1115-1127.

3. Jennings, R. B., and K. A. Reimer. 1983. Factors involved in salvaging ischemic myocardium: effect of reperfusion of arterial blood. Circulation. 68-I:I25-I-36. 
4. Farb, A., F. D. Kolodgie, M. Jenkins, and R. Virmani. 1993. Myocardial infarct extension during reperfusion after coronary artery occlusion: Pathologic evidence. J. Amer. Coll. Cardiol. 21:1245-1253.

5. Entman, M. L., L. Michael, R. D. Rossen, W. J. Dreyer, D. C. Anderson, A. A. Taylor, and W. C. Smith. 1991. Inflammation in the course of early myocardial ischemia. FASEB (Fed. Am. Soc. Exp. Biol.) J. 5:2529-2537.

6. Smith, E. F., J. W. Egan, P. J. Bugelski, L. M. Hillegass, D. E. Hill, and D. E. Griswold. 1988. Temporal relation between neutrophil accumulation and myocardial reperfusion injury. Am. J. Physiol. 255:H1060-H1068.

7. Garlick, P. B., M. J. Davies, D. J. Hearse, and T. F. Slater. 1987. Direct detection of free radicals in the reperfused rat heart using electron spin resonance spectroscopy. Circ. Res. 61:757-760.

8. Nayler, W. G., S. Panagiotopoulos, J. S. Elz, and M. J. Daly. 1988. Calcium mediated damage during post ischemic reperfusion. J. Mol. Cell. Cardiol. 20:4154.

9. Litt, M. R., R. W. Jeremy, H. F. Weisman, J. A. Winkelstein, and L. C. Becker. 1989. Neutrophil depletion limited to reperfusion reduces myocardial infarct size after 90 minutes of ischemia: evidence for neutrophil-mediated reperfusion injury. Circulation 80:1816-1827.

10. McCord, J. M. 1987. Oxygen-derived radicals: a link between reperfusion injury and inflammation. Fed. Proc. 46:2402-2406.

11. Zweier, J. L., J. T. Flaherty, and M. L. Weisfeldt. 1987. Direct measurement of free radical generation following reperfusion of ischemic myocardium. Proc. Natl. Acad. Sci. USA. 84:1404-1407.

12. Becker, L. C., J. Schaper, R. Jeremy, and W. Schaper. 1991. Severity of ischemia determines the occurrence of myocardial reperfusion injury. Circulation. 84:II-254.

13. Engler, R., and E. Gilpin. 1989. Can superoxide dismutase alter myocardial infarct size? Circulation. 79:1137-1142.

14. Sanford, N. L., J. W. Searle, and J. F. R. Kerr. 1984. Successive waves of apoptosis in the rat prostate after repeated withdrawal of testosterone stimulation. Pathology. 16:406-410.

15. Savill, J. S., A. H. Wyllie, J. E. Henson, M. J. Walport, P. M. Henson, and C. Haslett. 1989. Macrophage phagocytosis of aging neutrophils in inflammation. J. Clin. Invest. 83:865-875.

16. Wyllie, A. H., J. F. Kerr, and A. R. Currie. 1980. Cell death: the significance of apoptosis. Int. Rev. Cytol. 68:251-306.

17. Wyllie, A. H. 1980. Glucocorticoid-induced thymocyte apoptosis is associated with endogenous endonuclease activation. Nature (Lond.). 284:555-556.

18. Cotter, T. G., S. V. Lennon, J. G. Glynn, and S. J. Martin. 1990. Cell death via apoptosis and its relationship to growth, development and differentiation of both tumour and normal cells. Anticancer Res. 10:1153-1160.

19. Hockenbery, D. M., M. Zutter, W. Hickey, M. Nahm, and S. J. Korsmeyer. 1991. BCL2 protein is topographically restricted in tissues characterized by apoptotic cell death. Proc. Natl. Acad. Soc. USA. 88:6961-6965.

20. Searle, J., J. F. Kerr, and C. J. Bishop. 1982. Necrosis and apoptosis: distinct modes of cell death with fundamentally different significance. Pathol. Annu. 17:229-259.

21. Giannakis, C., I. J. Forbes, and P. D. Zalewski. 1991. $\mathrm{Ca}++/ \mathrm{Mg}++$ dependent nuclease: tissue distribution, relationship to inter-nucleosomal DNA fragmentation and inhibition by $\mathrm{Zn}++$. Biochem. Biophys. Res. Commun. 181:915-920.

22. Kleine, L., and M. Tenniswood. 1990. The biochemistry of cell death by apoptosis. Biochem. Cell Biol. 68:1071-1074.

23. Murgia, M., P. Pizzo, D. Sandon, P. Zanovello, R. Rizzuot, and F. DiVirgilio. 1992. Mitochondrial DNA is not fragmented during apoptosis. J. Biol. Chem. 267:10939-10941.

24. Tepper, C. G., and G. P. Studzinski. 1991. Teniposide induces nuclear but not mitochondrial DNA degradation. Cancer. Res. 52:3384-3390.

25. Kerr, J. F. R., A. H. Wyllie, and A. R. Currie. 1972. Apoptosis: A basic biological phenomenon with wide ranging implications in tissue kinetics. $B r . J$. Cancer. 26:239-257.

26. Wyllie, A. H., R. G. Morris, A. L. Smith, and D. Dunlop. 1884. Chromatin cleavage in apoptosis: association with condensed chromatin morphology and dependence on macromolecular synthesis. J. Pathol. 142:67-77.

27. Gaido, M. L., and J. A. Cidlowski. 1991. Identification, purification, and characterization of a calcium dependent endonuclease (NUC18) from apoptotic rat thymocytes. NUC18 is not histone H2B. J. Biol. Chem. 266:18580-18585.

28. Lennon, S. V., S. J. Martin, and T. G. Cotter. 1991. Dose dependent induction of apoptosis in human tumour cell lines by widely diverging stimuli. Cell Proliferation. 24:203-214.

29. Gavrieli, Y., Y. Sherman, and S. A. Ben-Sasson. 1992. Identification of programmed cell death in situ via specific labeling of nuclear DNA fragmentation. J. Cell. Biol. 119:493-501.

30. Wijsman, J. H., R. R. Jonker, R. Keijzer, C. J. van de Velde, C. J. Cornelisse, and J. H. van Dierendock. 1993. A new method to detect apoptosis in paraffin sections: In situ end-labeling of fragmented DNA. J. Histochem. Cytochem. 41:7-12.

31. Liu, G., J. Thornton, D. VanWinkle, A. Stanley, R. Olsson, and J. Downey. 1991. Protection against infarction afforded by preconditioning is mediated by A1 adenosine receptors in the rabbit heart. Circulation. 84:350-356.

32. Miura, T., J. M. Downey, H. Ootwa, S. Ogawa, T. Adachi, T. Noto, Y. Shizukuda, II, and O. Iimura. 1989. Progression of myocardial infarction in a collateral flow deficient species. Jpn. Heart J. 30:695-708.

33. Savill, J., I. Dransfield, N. Hogg, and C. Haslett. 1990. Vitronectin receptor mediated phagocytosis of cells undergoing apoptosis. Nature (Lond.). 343:170173.

34. Engler, R. L., G. W. Schmid-Schonbein, and R. S. Pavelec. 1983. Leukocyte capillary plugging in myocardial ischemia and reperfusion in the dog. Am. J. Pathol. 111:98-111.

35. Zakeri, Z. F., D. Quaglino, T. Latham, and R. A. Lockshin. 1993. Delayed internucleosomal DNA fragmentation in programmed cell death. FASEB (Fed. Am. Soc. Exp. Biol.) J. 7:470-478.

36. Ueda, N., and S. V. Shah. 1992. Endonuclease induced DNA damage and cell death in oxidant injury to renal tubular epithelial cells. J. Clin. Invest. 90:2593-2597.

37. Dipasquale, B., and R. J. Youle. 1992. Programmed cell death in heterokaryons. Am. J. Pathol. 141:1471-1479.

38. Smith, C. W., M. L. Entman, C. L. Lane, A. L. Beaudet, T. I. Ty, K Youker, H. K. Hawkins, and D. C. Anderson. 1991. Adherence of neutrophils to canine cardiac myocytes in vitro is dependent on intercellular adhesion molecule1. J. Clin. Invest. 88:1216-1223.

39. Youker, K., C. W. Smith, D. C. Anderson, D. Miller, L. H. Michael, R. D. Rossen, and M. L. Entman. 1992. Neutrophil adherence to isolated adult cardiac myocytes. Induction by cardiac lymph collected during ischemia and reperfusion. J. Clin. Invest. 89:602-609.

40. Kukielka, G., H. Hawkins, L. Michael, A. M. Manning, K. Youker, C. Lane, M. Entman, C. Smith, and D. C. Anderson. 1993. Regulation of intercellular adhesion molecule-1 (ICAM-1) in ischemic and reperfused canine myocardium. J. Clin. Invest 92:1504-1516.

41. Gobe, G. C., R. A. Alexsen, and J. W. Searle. 1990. Cellular events in experimental unilateral ischemic renal atrophy and in regeneration after contralateral nephrectomy. Lab. Invest. 63:770-779.

42. Schumer, M., M. C. Colombel, I. S. Sawczuk, G. Gobe, J. Connor, K. M O'Toole, G. J. Wise, and R. Buttyan. 1992. Morphologic, biochemical, and molecular evidence of apoptosis during the reperfusion phase after brief periods of renal ischemia. Am. J. Pathol. 140:831-838.

43. Mangan, D. F., and S. M. Wahl. 1991. Differential regulation of human monocyte programmed cell death (apoptosis) by chemotactic factors and proinflammatory cytokines. J. Immunol. 147:3408-3412.

44. Migliorati, G., C. Pagliacci, R. Moraca, F. Crocicchio, I. Nicolete, and C. Riccardi. 1992. Interleukins modulate glucocorticoid induced thymocyte apoptosis. Int. J. Clin. Lab. Res. 21:300-303.

45. Shirato, C., T. Miura, H. Ooiwa, T. Toyofuku, W. H. Wilborn, and J. M. Downey. 1989. Tetrazolium artifactually indicates superoxide dismutase-induced salvage in reperfused rabbit heart. J. Mol. Cell. Cardiol. 21:1187-1193.

46. Matsumura, K., R. Jeremy, and L. C. Becker. 1990. Loss of myocardial viability during reperfusion demonstrated by paired measurements of 2-deoxyglucose uptake. Circulation. 82:III-754 (Abstr.) 